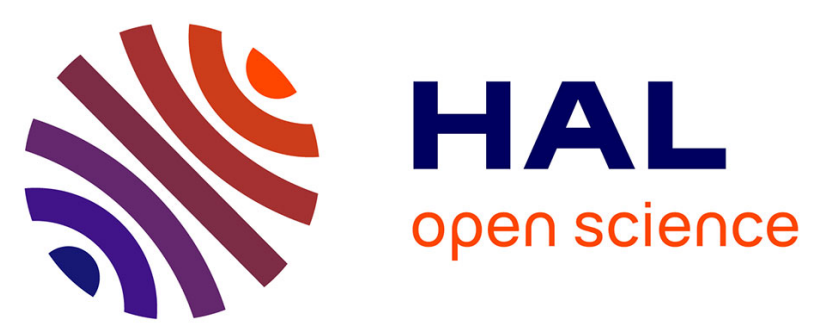

\title{
Who Will Be the Leaders in Top Academic Positions in Entertainment Computing?
}

Letizia Jaccheri, Soudabeh Khodambashi, Katrien De Moor, Özlem Özgöbek, Katina Kralevska

\section{- To cite this version:}

Letizia Jaccheri, Soudabeh Khodambashi, Katrien De Moor, Özlem Özgöbek, Katina Kralevska. Who Will Be the Leaders in Top Academic Positions in Entertainment Computing?. 17th International Conference on Entertainment Computing (ICEC), Sep 2018, Poznan, Poland. pp.392-396, 10.1007/9783-319-99426-0_49 . hal-02128603

\section{HAL Id: hal-02128603 \\ https://hal.inria.fr/hal-02128603}

Submitted on 14 May 2019

HAL is a multi-disciplinary open access archive for the deposit and dissemination of scientific research documents, whether they are published or not. The documents may come from teaching and research institutions in France or abroad, or from public or private research centers.
L'archive ouverte pluridisciplinaire HAL, est destinée au dépôt et à la diffusion de documents scientifiques de niveau recherche, publiés ou non, émanant des établissements d'enseignement et de recherche français ou étrangers, des laboratoires publics ou privés. 


\title{
Who Will Be the Leaders in Top Academic Positions in Entertainment Computing?
}

\author{
L. Jaccheri ${ }^{1}$, S. Khodambashi ${ }^{1}$, K. De Moor ${ }^{2}$, Ö. Özgöbek ${ }^{1}$, K. Kralevska ${ }^{2}$ \\ 1 Department of Computer Science, NTNU, Norway \\ 2 Department of Information Security and Communication Technology, NTNU, \\ Norway \\ \{letizia.jaccheri, soudabeh, katrien.demoor, ozlem.ozgobek, katinak\}@ntnu.no
}

\begin{abstract}
To address the issue of under-represented women in Entertainment Computing (EC), this paper builds on a set of theoretical references and ongoing projects to propose a set of guidelines that can be used to set up projects to improve inclusion of female and other people at risk of exclusion in top academic positions in STEM and in Entertainment Computing. This set is fourfold, including: 1. knowledge development phase; 2. a strategy development and implementation process; 3 . a push for strategic international networking, deploying mentors closely aligned to the aforementioned strategy; and 4. sharing the project's findings with the community.
\end{abstract}

Keywords: Gender equality, gender balance, gender imbalance, STEM, entertainment computing, mentoring, internationalization

\section{Introduction}

Gender balance within STEM (Science, Technology, Engineering and Mathematics) education and research is a well established scientific field [?] [?,?,?]. Moreover, more women than men drop out of academic STEM careers. This does not only contribute to gender bias in research (sex differences in study design and analysis), but also results in an under-representation of women in leading positions, a loss of talent for society and a lack of diversity in the workplace, each of which presents a potential threat to the search for excellence in research [?,?].

In particular, gender issues in EC have been a hot topic in the last few years. Theoretical references and concrete suggestions have been addressed in [?] and [?]. For instance, of the twenty-eighth IFIP Technical Committee 14 (Entertainment Computing) National representatives only three are women. This under-representation of women also has implications for research in the field of Entertainment Computing and for the too limited inclusion of a more diverse set of perspectives and approaches, which would allow to reflect the diversity in the society in a better way.

Furthermore, even though we here predominantly focus on gender, gender is not the only aspect impacting diversity that needs to be considered. European 
STEM departments in the broad sense exhibit a strong predominance of men, but also of a strong international profile. This introduces another diversity dimension with both potential gains and challenges in terms of cultural differences. Significant portions of women who study and work in STEM at European universities are international. However, women's social capital is hampered by the fact that women are often excluded from influential international networks [?] (for instance, the earlier example of the IFIP Technical Committee), and that women seem to use the networks in a different way than men - to fulfill social objectives rather than career objectives [?].

Several previous research projects [?,?,?] have - often individually - approached issues of gender bias in STEM employment at different academic and industry levels, but rarely within a comprehensive framework or from a more holistic view (e.g., considering not only gender but also origins and cultural background jointly). Integrating these lessons could create a renewed push for gender equality in STEM and its sub-fields and may potentially be transferable to other diversity traits and characteristics. On the one hand, although improvements have been and continue to be made, there remains a long way to go with regards to increasing the share of top positions occupied by women. The persisting low percentage of women at the student level must be scrutinized in connection to gender imbalance at the professor level. Is a lack of role models at the highest level a contributing factor to women being less likely to be recruited to entry-level research positions and more likely to drop out of academic career pathways? Several studies have looked at the inter-sectional experiences of being a female and a foreigner in an academic context, each reaching conclusions useful to this study but demanding more emphasis on the individual's own perspective [?,?]. The need for more in-depth knowledge of the interaction between international mobility and gender equality in academia is thus great. STEM departments' tendency toward excellent international profiles could be used as a resource for better national and international recruitment of female academics, and better networking between recruits to support each other as they continue their academic journeys.

With the increasing awareness of the gender imbalance, many national and international gender balance projects have started. The international projects and networks, such as ACM Council on Women in Computing ${ }^{3}$, IEEE Women in Engineering ${ }^{4}$, Grace Hopper Celebration ${ }^{5}$, European Center for Women and Technology ${ }^{6}$ and European Women in Mathematics ${ }^{7}$, provide us a wide perspective on the necessity, sustainability and broad dissemination opportunities of gender balance projects.

\footnotetext{
3 https://women.acm.org

4 http://wie.ieee.org

${ }^{5}$ http://gracehopper.org

${ }^{6}$ http://www.ecwt.eu/en/home

7 www.europeanwomeninmaths.org
} 
Our work is guided by two objectives: sustain participation of girls of diverse backgrounds and raising awareness for intersectionality of gender with other dimensions such as race and class among researchers).

\section{Guidelines}

Based on these local initiatives, best practices and related work, we propose a framework consisting of four main guidelines that can be integrated into projects or initiatives aimed at improving the gender balance in top academic positions in STEM. We advocate a holistic view of gender representation in STEM all the way from the level of student to that of professor, and one in which internationalization is used consistently as both a lens through which to view participant's experiences and as a resource to help overcome the disadvantages of gender bias and working abroad. These four pillars (knowledge, a strategy development process, international networking and mentoring and knowledge sharing) can be considered as essential elements to incorporate in strategic initiatives that aim to foster a better gender balance and that may be transferable/applicable to imbalance and threats to diversity linked to other variables (e.g., class, ethnicity, social-cultural background).

Guideline 1 - Knowledge integration Many projects, local initiatives and measures exist to overcome the gender inequality in academia, but their impact may remain limited if not integrated into a more holistic knowledge base. In an initial phase it is therefore of crucial importance to gather and integrate insights from previous and ongoing projects: what can we learn from these (e.g., (un)successful measures)? What are main challenges and how/at which level should they be addressed? Developing such a knowledge base - as an essential foundation for strategy development - thus means gaining a more thorough understanding of relevant broad issues and theories, gathering ideas for action, evaluating experiences with the implementation of different types of measures.

Guideline 2 - Strategy development (targeting cultural and structural management changes) This activity involves initiating and building up a long-term strategic process to develop good measures to improve equality and diversity as represented by academic recruitment and appointment. A potential approach to this strategic development process is that two groups across departments work together in a common strategy-development process. One strategy process research group consists of men and women in academic positions. The second group consists of faculty management. Diversification issues and internationalization are important for both groups, but may be managed in different ways. An essential question here is therefore how to manage processes in academia with a focus on gender balance? Strategy process research group should run throughout the project period, in a participant-centered and iterative way. By implementing a strategy to gather and share knowledge, applied reflections and practical measures over time, there is a potential to affect cul- 
tural conditions - not just for those who are directly involved, but at the level of institutions as a whole.

Guideline 3 - International networking and mentoring A large proportion of female STEM students and employees at European institutions have a foreign background, and many institutional activities are internationally directed, with international partners and the possibility of international recruitment. A third guideline is therefore to set up a dedicated networking and mentoring program to recruit, retain and lift up female (inter)national employees to the next level. Several international studies have shown that academic mentoring is experienced as beneficial for both mentors and mentees and that it can be an important career development instrument [?].

Senior faculty members and a pool of adjunct professors from Industry and from International Universities could be assigned to assist with mentoring, career guidance and international networking for employees in the various categories. The institution as a whole can play an important role here by encouraging and incentivizing the development of a mentoring culture. It can also contribute with the development of a set of best practices for academic mentoring, with for instance clear descriptions on the roles and responsibilities of mentor and mentee, organization of networking events for mentors and mentees, sharing of experiences and best practices with academic mentoring, etc.

Guideline 4 - Sharing An important target group for the dissemination of the results will be the faculty staff of departments directly involved in the investigation. More broadly, the resulting findings and suggestions may be adapted for audiences at STEM departments that exhibit a similarly skewed diversity balance in occupation of top-level positions. Finally, the findings and recommendations of the project will be conveyed nationally (through blog, social media, articles and other dissemination activities) and internationally (through participation in international conferences and networking activities, especially those with a front-and-centre focus on gender).

\section{Conclusions and Future work}

In order to improve balance of gender and other dimensions such as race and class among researchers in STEM fields in general and EC in particular, it is important to increase the percentage of women and people with diverse race and class background in academic positions. We have proposed a set of guidelines based on a four pillars cycle. We have started to implemented these guidelines in the WeLead project at NTNU and we are in the process of establishing a follow up project which will systematically implement them. Further, monitoring and evaluation of implementation can provide more insights about the four pillars which can benefit researchers for reusing the results. Our future work can benefit from creating a clear connection between the local, National, and International networks (with focus on the the EC community) and will explore in more detail how the general guidelines and their results could be transferred and applied to imbalance linked to other diversity dimensions. 


\section{Acknowledgements}

This work was partially supported by the WeLead program at NTNU. 